\title{
Devic Disease in Senegal, a West African Country: About Five Cases
}

\author{
Dadah Samy Mohamed Lemine ${ }^{1}$, Cisse Ousmane ${ }^{1}$, Boubacar Soumaila ${ }^{1}$, Kyelem Kafando Julie \\ Marie Adeline $^{1}$, Sow Adjaratou Djeynaba ${ }^{1}$, Diallo Ibrahima Mariam ${ }^{1}$, Takam Valerie Innes ${ }^{1}$, \\ Faye Mohameth $^{2}$, Ba El Hadji Makhtar ${ }^{1,3}$, Ndiaye Papa Ibrahima ${ }^{1}$, Diagne Ngor Side ${ }^{1}$, Seck \\ Lala Bouna ${ }^{1}$, Sarr Mamadou ${ }^{4}$, Toure Kamadore ${ }^{1,5}$, Ndiaye Moustapha ${ }^{1}$, Diop Amadou Gallo ${ }^{1}$, \\ Ndiaye Mouhamadou Mansour ${ }^{1}$ \\ ${ }^{I}$ Department of Neurology, Fann National Teaching Hospital, Dakar, Senegal \\ ${ }^{2}$ Department of Neurosurgery, Fann National Teaching Hospital, Dakar, Senegal \\ ${ }^{3}$ Department of Psychiatry, Fann National Teaching Hospital, Dakar, Senegal \\ ${ }^{4}$ Health Science Unity, Regional Hospital of Thiès, Senegal \\ ${ }^{5}$ Department of Public Health and Preventive Medicine
}

*Corresponding Author: Dadah Samy Mohamed Lemine, Department of Neurology, Fann National

Teaching Hospital, Dakar, Senegal,E-mail:ouscis01@hotmail.fr

Received : March 31, 2017

Accepted: April 13, 2017

Published: April 25, 2017

Abstract: Neuromyelitis optica (NMO), also known as Devic Disease, is characterized by association of subacute myelitis and unilateral or bilateral acute optic neuropathy. In African context, this pathology remains undervalued. We report five cases of NMO hospitalized at the Neurological Clinic of Fann Teaching Hospital. These patients had been admitted for sub-acute tetraplegia associated with a visual acuity disability. Medullar MRI showed a T2 hypersignal extended more than three segments of vertebrae and visual evoked potentials showed a bilateral retro bulbar optic neuritis. The study of cerebrospinal fluid showed hypercytose and high level of protein. Evolution under corticosteroids was marked by an improvement of motor deficit but with persistence of ocular signs. NMO is a clinical entity that may be underdiagnosed in sub-Saharan Africa because of lack of access to diagnostics such as MRI and dosage of anti-NMO antibodies.

Keywords: Devic Neuromyelitis optica, Senegal

\section{INTRODUCTION}

Devic disease or neuromyelitis optica (NMO) is an inflammatory and demyelinating disease of the central nervous system (CNS) characterized by a uni or bilateral optic neuritis and an acute or subacute myelitis. Long considered as a rare and particular form of multiple sclerosis (MS), recent fundamental studies confirm the difference between NMO and MS. Recent discovery of a very specific antibody (antibody anti-NMO) but with imperfect sensitivity (50$70 \%$ ) $[1,2]$, permit to more characterize spectrum of NMO [3]. Recently, it was shown a possible deleterious role of antibodies antiaquaporin4 (AQP4) with a loss of expression of AQP-4 in NMO lesions than in MS, where there is rather an over expression of the AQP-4. NMO is pathology of humoral immunity and should be seen more as a Vasculitis of central nervous system than a demyelinating disease. Immunosuppressive therapy appears to be a therapeutic option [4].

Epidemiological surveys show preferential susceptibility in sub-Saharan African populations to the NMO [16]. The interest of this work is the scarcity of African publications on the subject. We discuss five observations of NMO selected on the basis of diagnostic criteria proposed by Wingerchuk in 2006 [5, 6].

\section{OBSERVATIONS}

\subsection{Observation $n 1$}

It was a 21 years old woman without pathological history, followed since April 2011 for a motor deficit on his four members rapidly progressive in a few days which had motivated a 
consultation in the Neurological Department of Fann Teaching hospital. Symptomatology was complete by a bilateral reduction of visual acuity. Patient presented a good general condition with normal blood pressure and normal temperature. Examination just found spastic tetraplegia at $0 / 5$ according to the quotation of the Medical Research Council (MRC) and a severe decrease in visual acuity.

Magnetic resonance imaging (MRI) showed a $\mathrm{T} 2$ hypersignal and $\mathrm{T} 1$ hyposignal intra Medullar lesion extended from $\mathrm{C} 1$ to $\mathrm{C} 4$ without raising after gadolinium's injection. Brain MRI was normal.

Visual evoked potential (VEP) showed a severe bilateral axonal achievement of optic nerve with on right a P100 wave at $113,20 \mathrm{~ms}$ (Normal $<100 \mathrm{~ms}$ ) latency and amplitude 0 (Normal $>5 \mu \mathrm{V})$ and on left a P100 wave latency at $110 \mathrm{~ms}$ and amplitude at $0,77 \mu \mathrm{V}$.

Cerebrospinal fluid analysis objectified pleocytosis with 48 elements per mm3 with more lymphocytes, a high level of proteins at 0 . $67 \mathrm{~g} / \mathrm{l}$ (Normal: 0.15 to $0.45 \mathrm{~g} / \mathrm{l}$ ). Immuneelectrophoresis of proteins in cerebrospinal fluid (CSF) didn't showed supernumerary bands with just albumin at $2,53 \mathrm{mg} / \mathrm{l}(\mathrm{N}: 150-350)$ and increasing of intrathecal $\mathrm{IgG}$ synthesis. Bacteriological culture and research of bacterial antigens was negative for haemophilus influenzae type $b, s$. pneumoniae, neisseria meningitidis $\mathrm{B} / \mathrm{C}$, Eischerischia Coli K1. The blood numeration, sedimentation rate and CRP were normal. Others blood assessments as hepatic, renal, ionic, lipid, carbohydrate and coagulation were also normal. HIV and syphilitic serology were negative.

The diagnosis of NMO was chosen and patient put in corticosteroid therapy at $1 \mathrm{mg} / \mathrm{kg} / \mathrm{day}$. Evolution was marked by a complete recovery of motor functions in $5 / 5$ according to the MRC scale with more late recovery of vision in two months. We did a gradual regression of corticosteroid therapy.After stopping steroid treatment and the occurrence of pregnancy, appeared, in a few day, motor troubles and a rapid decline of visual acuity. Corticosteroid therapy has been reintroduced with improvement of motor disturbances and persistence of bilateral blindness.
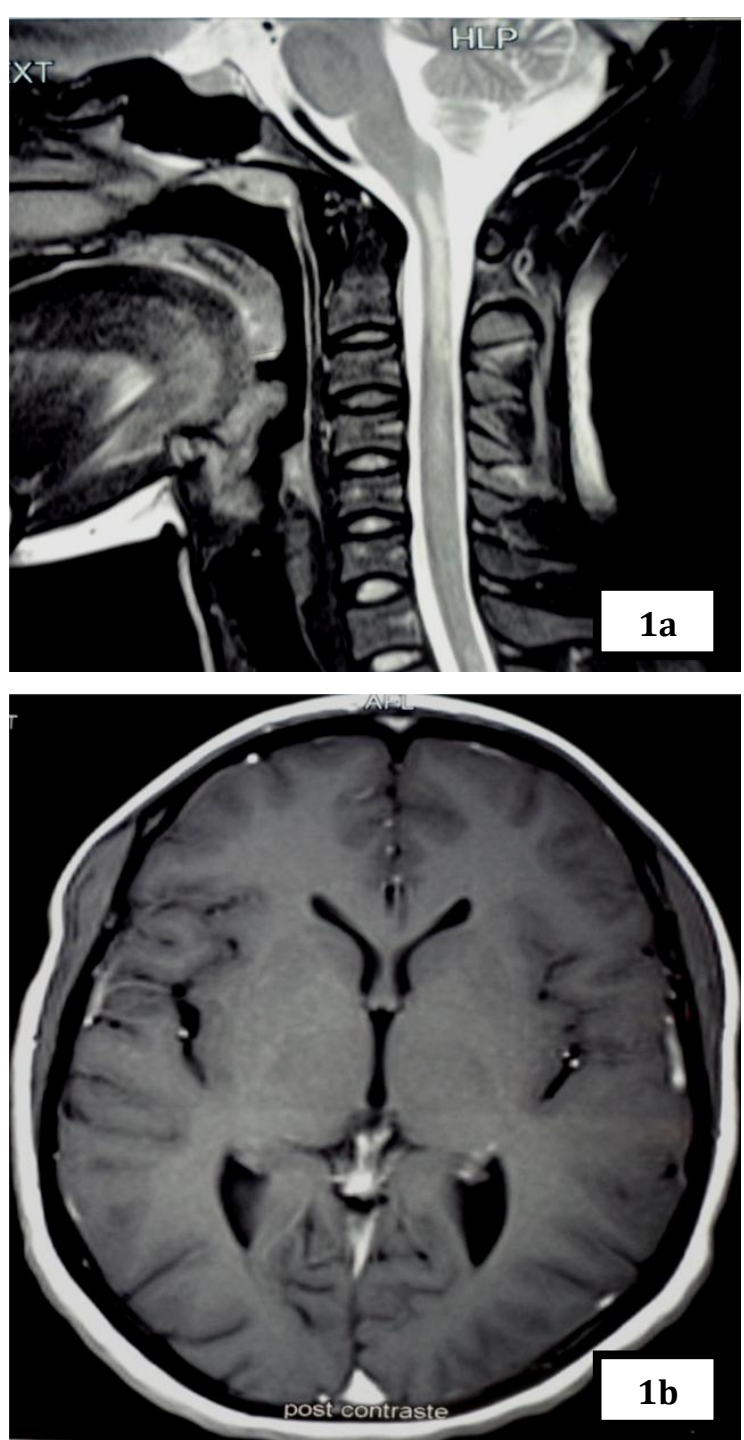

Figure1. Spinal cord and cerebral MRI

a.Intramedullar T2 hypersignal extended from $\mathrm{Cl}$ to C4 in sagittal coupe

b.Normal cerebral MRI in FLAIR axiale coupe

\subsection{Observation n2}

This was a 48 years old man, without any specific pathological history, hospitalized in the Neurological Department of Fann Teaching Hospital in January 2013 for 4 members' motor deficit and visual disturbances. The beginning was sudden 2 weeks ago with occurrence of a dyschromatopsia followed by a bilateral reduction of visual acuity and a week later by a complete deficit of four members, starting in the lower limb without any specific context as fever or general alteration.

At the admission, physical examination showed flaccid tetraplegia (listed at 0/5 scale MRC) with hypotonia and reflex abolition, associated with sensory disorders, as no systematized touch and painful hypoesthesia, and urinary incontinence. The ophthalmologic examination found a 
decrease of bilateral visual acuity with dyschromatopsia.

Our patient had done a spinal MRI which showed a volumes' increasing of spinal cord with a T2 intramedullary hypersignal extended from C2 to C6, which was on T1 hyposignal and was enhanced by gadolinium's injection. Brain MRI was normal.

The VEP showed bilateral axonal damage of optic nerve with on right a latency of $\mathrm{P} 100$ wave at $112,40(\mathrm{~N}<100 \mathrm{~ms})$ with an amplitude at 1 , $3 \mu \mathrm{V}(\mathrm{N}>5 \mu \mathrm{V})$, and on left a $\mathrm{P} 100$ wave at respectively $106,60 \mathrm{~ms}$ and $2,9 \mu \mathrm{V}$ as latency and amplitude.

The cerebrospinal fluid analysis objectified a hypercytosis with 51 lymphocytes/mm3 and a discreet well (proteins' increasing) at $0.53 \mathrm{~g} / \mathrm{l}$ (Normal: 0,15 à $0,45 \mathrm{~g} / \mathrm{l}$ ). Bacteriological culture and research of bacterial antigens was negative for haemophilus influenzae $\mathrm{B}, \mathrm{s}$. pneumoniae, neisseria meningitidis $\mathrm{B} / \mathrm{C}$, Eischerischia Coli K1. Virus' searching in the CSF (herpes virus, enterovirus) was negative.

Biology found a Leukocytosis at 11300 with principally neutrophil. The sedimentation rate was at $5 \mathrm{~mm}$ in the first hour and CRP at 48 $\mathrm{mg} / \mathrm{l}$. Others blood assessments as hepatic, renal, ionic, lipid, carbohydrate and coagulation were normal. HIV and syphilitic serology were also negative.

Our patient had received methylprednisolone' $\mathrm{s}$ bolus at $1 \mathrm{~g} /$ day during 3 days with oral prednisone relay at $1 \mathrm{mg} / \mathrm{kg} / \mathrm{day}$.

Evolution was marked during 3 weeks' hospitalization by a clinical improvement with a recovery of motor force at 3/5 (depending on the MRC scale) and persistence of visual disturbances.

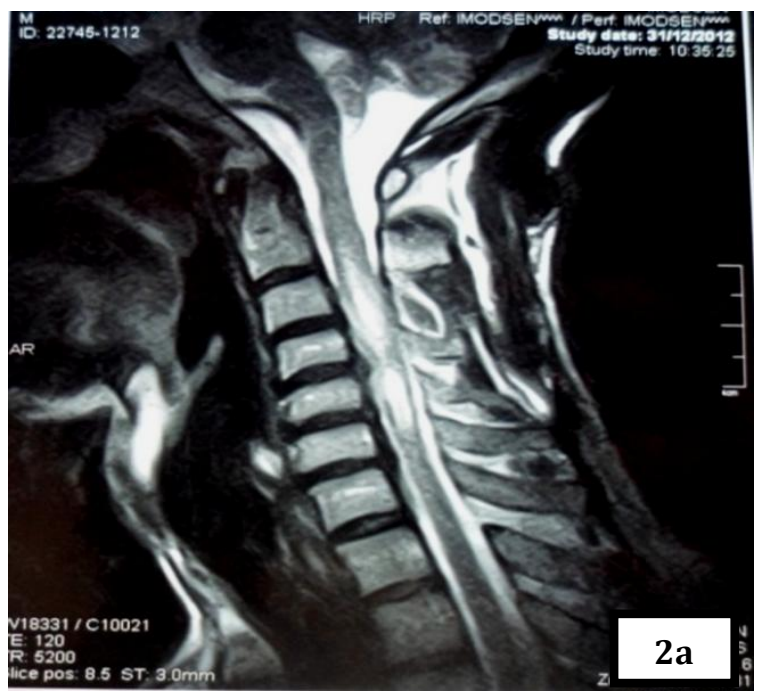

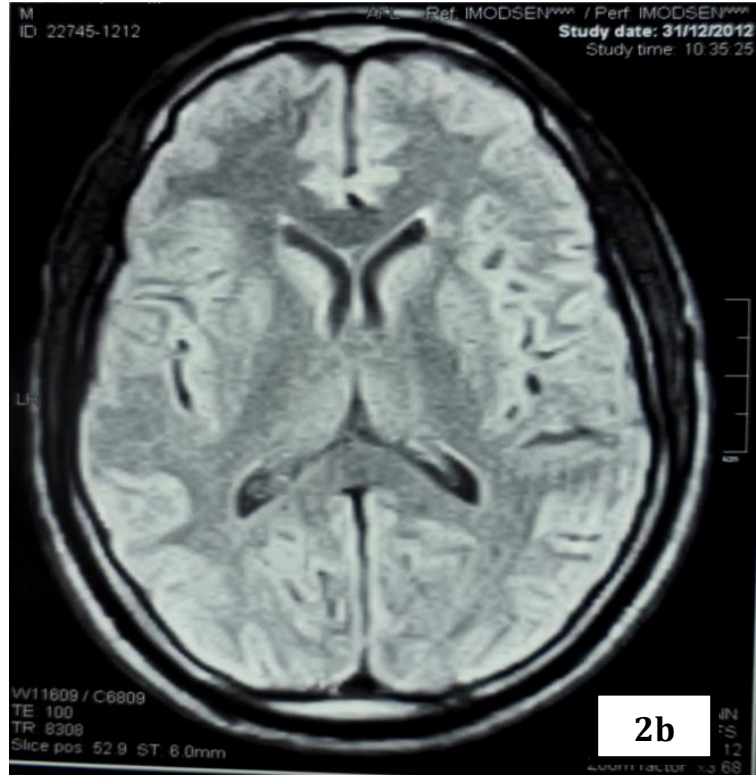

Figure2. Spinal cord and cerebral MRI

a. Intramedullar T2 hypersignal extended from $C 2$ to
C6 in sagittal coupe

b: Normal cerebral MRI in FLAIR axiale coupe

\subsection{Observation $\mathrm{n} 3$}

It was an 18-year-old boy, student hospitalized from $2012-12-28$ to $18 / 01 / 2013$ for a bilateral reduction of visual acuity and a 4 member's motor deficit with rapid onset in 24 hours preceded by cervical pain. The patient presented sphincter disorders as acute urine retention. There was no concept of history of known chronic pathology, nor of recent infection or recent vaccination.

Patient's examination showed a good condition with normal blood pressure $(120 / 80 \mathrm{mmHg})$, without fever $\left(36.5{ }^{\circ} \mathrm{C}\right)$ and a heart rate at 76 beats/min. Neurological examination found tetraplegia with a motor force at $0 / 5$ on left part of body and 2/5 on the right (according to the MRC scale) with reflexes' abolition on 4 members and abolition of Algesic sensitivity was below from $\mathrm{C} 4$ without prejudice of tactile and deep. The neck was flexible and examination of the cranial nerves was normal. The rest of review was normal.

Spinal cord MRI showed a T2 hypersignal lesion extended from C2 to C6 which appeared by $\mathrm{T} 1$ isosignal, with aspect of enlarged spinal cord and enhanced with gadolinium. Brain MRI was normal.

The VEP showed bilateral axonal damage of optic nerve with on right the P100 wave latency and amplitude respectively at $105,00 \mathrm{~ms}$ $(\mathrm{N}<100 \mathrm{~ms})$ and $0.9 \mu \mathrm{V}(\mathrm{N}>5 \mu \mathrm{V})$, and on left at $110,20 \mathrm{~ms}$ and $0.4 \mu \mathrm{V}$. 
Cerebrospinal fluid analysis objectified cytology with 15 elements $/ \mathrm{mm} 3$ and an high level of proteins at $0.56 \mathrm{~g} / \mathrm{l}$ (Normal: 0.15 to $0.45 \mathrm{~g} / \mathrm{l}$ ). Bacteriological culture and research of bacterial antigens was negative for haemophilus influenzae $\mathrm{B}$, s. pneumoniae, neisseria meningitidis B/C, Eischerischia Coli K1.

The blood numeration and sedimentation rate in the first hour were normal with a CRP at $6 \mathrm{mg} / \mathrm{l}$. Others blood assessments as hepatic, renal, ionic, lipid, carbohydrate and coagulation were normal. HIV and syphilitic serology were negative.

After treatment by prednisone at $1 \mathrm{mg} / \mathrm{kg} / \mathrm{day}$, evolution was marked, in 10 days of hospitalization, by a clinical improvement with a recovery of the motor force to $3 / 5$ left and 4/5 right (according to the MRC scale).
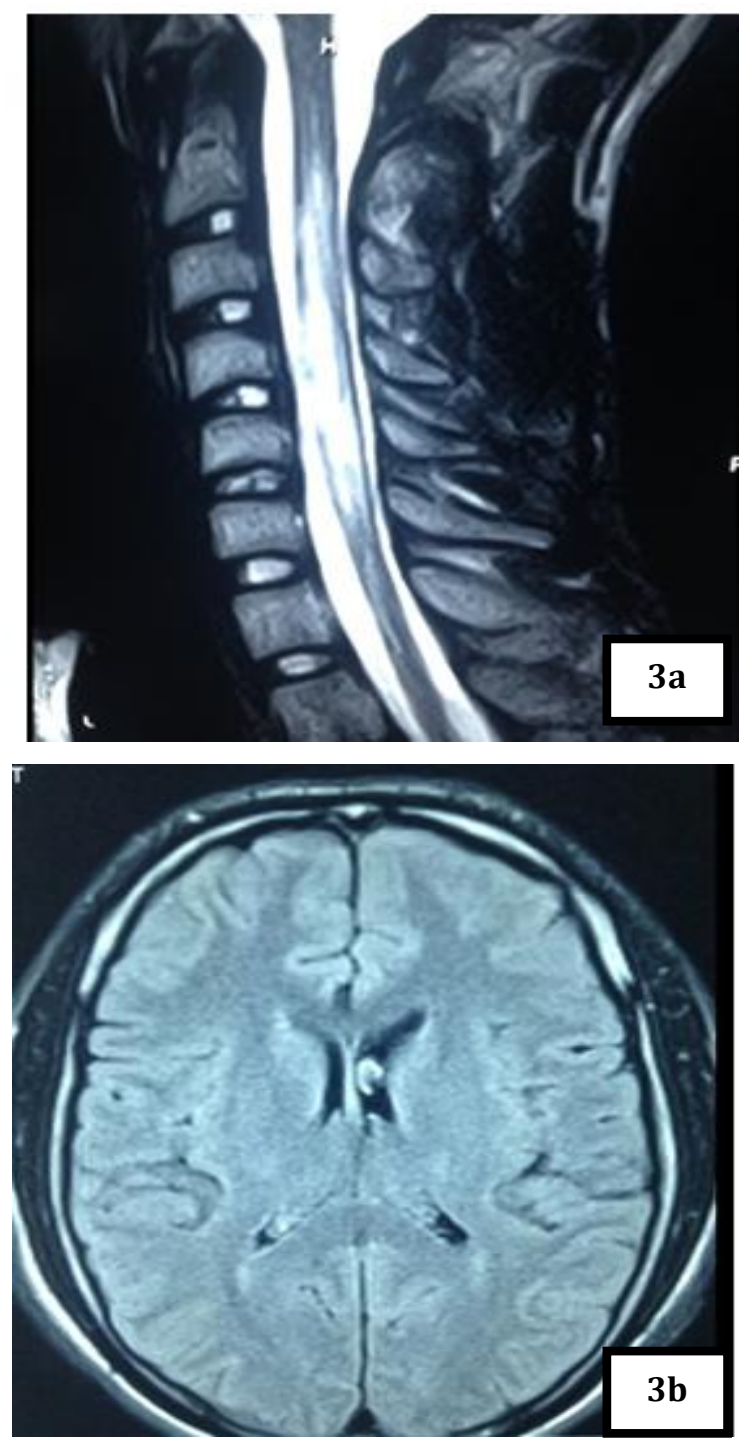

Figure3. Spinal cord and cerebral MRI
a. Intramedullar T2 hypersignal extended from $\mathrm{C} 2$ to C6 in sagittal coupe

b. Normal cerebral MRI in FLAIR axiale coupe

\subsection{Observation $\mathrm{n} 4$}

We had a 35 years old woman, whose last pregnancy dates back to 3 months without any specific pathological history except a visual acuity decrease on his left eye 1 year ago which had regressed spontaneously.

She was hospitalized in our service in May 2014 after a rapidly progressive installation during 10 days, without any particular circumstances, of recidivism of his left eye visual acuity decrease associated with neck and dorsal pain (D4 - D6) of moderate intensity with downward radiation complicated by a motor deficit. The deficit began to left lower limb then lower extremity right then to the left upper limb to finally reach the upper limb right.

The review found a good condition with a blood pressure at $120 / 60 \mathrm{~mm} \mathrm{Hg}$, and a normal temperature at $37.5{ }^{\circ} \mathrm{C}$. Neurological examination showed a flaccid asymmetric tetraparesis with a motor force at $0 / 5$ on the left limb, $3 / 5$ on the left arm, 4/5 on the right arm and $5 / 5$ on the right limb (according to the MRC scale). Bilateral plantar cutaneous reflexes were in extension (Babinski); those abdominal skins were abolished at all levels. We had an none systematized sensory troubles below cervical spine. Sphincter disorders found were urinary incontinence and constipation. The rest of the examination was normal.

Spinal cord MRI showed a T2 hypersignal on cervical and dorsal from C2 to D4 without massive effect and without enhancement of lesions on gadolinium. The marrow was normal volume. Brain MRI was normal.

The VEP had shown a desynchronization of the responses indicating a very severe bilateral demyelinating of optic nerves.

The Cerebrospinal fluid showed a pleocytosis with 36 elements $/ \mathrm{mm}^{3}$ and a high level of proteins $0.56 \mathrm{~g} / \mathrm{l}$ (Normal: 0.15 to $0.45 \mathrm{~g} / \mathrm{l}$ ). Bacteriological culture and research of bacterial antigens was negative for haemophilus influenzae $\mathrm{B}, \mathrm{s}$. pneumoniae, neisseria meningitidis $\mathrm{B} / \mathrm{C}$, Eischerischia Coli $\mathrm{K} 1$. Viruses, fungus and parasitse research was negative in the CSF.

The blood numeration was normal, CRP negative and sedimentation rate accelerated. The others blood assessments, as hepatic, renal, ionic, carbohydrate and clotting, were normal. The retrovirus (HIV, HTLV) and syphilis serology were negative. 
Our patient received Prednisone at $1 \mathrm{mg} / \mathrm{kg} / \mathrm{day}$, associated with adjuvant therapy, analgesics and a motor rehabilitation. After 1 month the motor deficit had declined but with persistence of genito-sphincterial troubles.

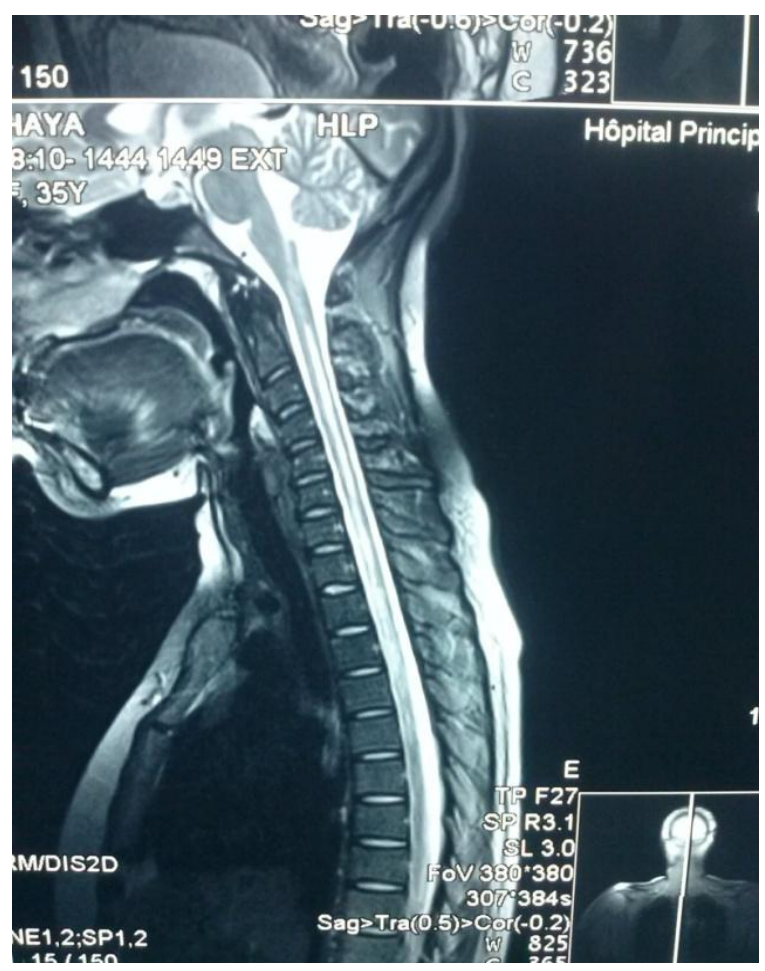

Figure4. Spinal cord MRI Intramedullar T2 hypersignal extended from C2 to T6 in sagittal coupe

\subsection{Observation n5}

It was a 50 years old woman without no specific pathological history, hospitalized in our service for dorsal pain radiating in right hemi-belt with a weakness of the lower limb, associated with acute urine retention without context of fever. A month later occurred a sudden bilateral visual acuity decrease.

Patient had a good condition with a blood pressure at $110 / 70 \mathrm{mmHg}$ and temperature at $36.9{ }^{\circ} \mathrm{C}$. Neurological examination found paraplegia with a motor force at $0 / 5$ to 2 lower limbs (according to the MRC scale); osteotendinous reflexes were abolished at the 2 lower limbs with bilateral Babinski sign. Touch superficial sensitivity was decreased below D6 with conservation of deep sensitivities on 4 members. The neck was flexible and review of the cranial nerves was normal, the rest of exam also.

Spinal cord MRI showed a T2 hypersignal from C6 to D6, with enhancement of lesions with gadolinium. Visual evoked potential (VEP) highlighted a severe bilateral axonal achievement of optic nerves.
The CSF study showed was normal with lelement/mm3 and proteins rate in normal limits.

The blood numeration showed a Leukocytosis, principally polynucleosis, with an acceleration of the sedimentation rate and CRP elevation. The hepatic, renal, ionic, carbohydrate and clotting assessments were normal. HIV and HTLV serology were negative.

This patient received $1 \mathrm{mg} / \mathrm{kg} /$ day of Prednisone, with adjuvant therapy, analgesic treatment and motor rehabilitation. The evolution was stationary with persistence of the motor deficit and patient went out against medical advice for testing traditional cure.

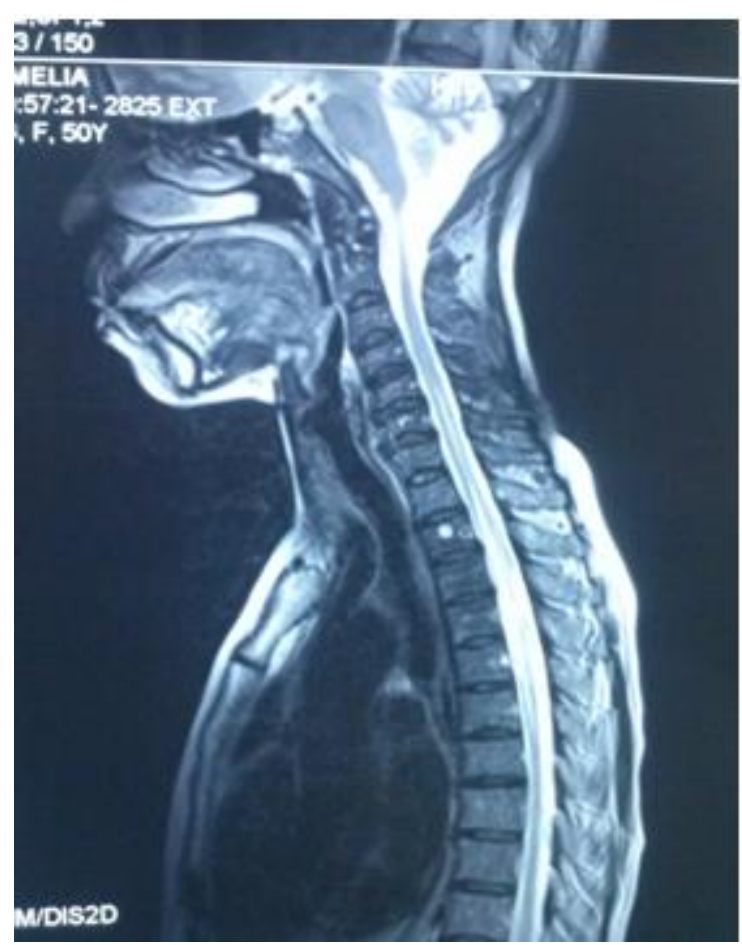

Figure5. Spinal cord MRI Intramedullar T2 hypersignal extended from C3 to T5 in sagittal coupe

\section{DISCUSSION}

The Devic neuromyelitis optica retained in our 5 patients were based on the revised criteria proposed by Wingerchuk in 2006 [4] combining 2 major criteria optic neuritis and an acute myelitis with at least two of the following three secondary criteria: * A spinal cord MRI with contiguous signal anomalies extended over more than three vertebral segments; * A brain MRI without diagnosis criteria of multiple sclerosis; * A positive NMO - IgG serology.

Cabre and al. [16] found a preferential susceptibility of afro-Caribbean populations for NMO. Then, they report a high prevalence of 
NMO in Martinique and Guadeloupe where NMO seems to be more common than MS. These regions are composed by African descendants. But few studies on the NMO were made in African continent [16]. This may be the result of a under-diagnosis due to an insufficient technical platform. Some environmental factors influencing the incidence of the NMO in Africa could also be evoqued.

The clinical symptoms of eye and spinal cord confirmed by data of others paraclinical examinations including the VEP, which showed bilateral optical impairment, and spinal cord MRI which highlighted a T2 hypersignal extended more than three vertebral segments without brain involvement on MRI in our five patients were the reasons of evoking the DEVIC NMO.

Spinal cord MRI of our patients showed on cervical spinal cord, a T2 hyper signal and T1 hyposignal intramedullary lesion, lying on at least 3 segments of vertebrae, without enhanced by gadolinium's injection in the 21 years old patient and with enhanced and spinal volume's increasing in the 48 years old and 18 years old patients. These results are concordant with those of Papeix [9] which included an intra-Medullary image T2hypersignal - T1 hypo signal and volume's increase of the spinal cord with earlier initial enhancement which disappearing remotely. The same study [9] mentioned the unique character of myelitis with predominant localization to cervical and thoracic level that we also observed in our study.

Cerebrospinal fluid analysis of our patients had shown a lymphocytic predominance hyper cytose and a high level of proteins' rate. These results were close to those found in several studies $[7,8,10,11,12]$. The Highlighting in our patients of oligoclonal $\operatorname{IgG}$ profile with intrathecal $\operatorname{IgG}$ synthesis was strongly suggestive of a chronic inflammatory disease of the brain [14]. The presence of bands in the CSF oligoclonal is variable with an intrathecal immunoglobulin synthesis in $23 \%$ of cases.

Devic disease diagnosis was retained in our patients without effective determination of the anti-NMO-IgG and anti-AQP4 Antibodies. The study of Barateau and al. [17] showed difficulties in diagnosis in case of negativity of AQP4/NMO-IgG antibodies. But, because of emergency of NMO, the negativity of antibodies should not delay the treatment, especially because of their relative low sensibility estimate to $50-70 \%$ according to some studies $[18,19]$.

According to Garcia et al [15], the optical damage in NMO, with axonal loss, appears to be more serious than in multiple sclerosis, explaining the persistence of visual disorders despite the recovery of the motor functions in patients after corticosteroid therapy. The evolution in the 20 years old patient was marked by the occurrence of another boost complicated by a bilateral blindness. Ben cherifa [13] found in his study, a first thrust of NMO on pregnancy. Pregnancy could be a factor in triggering or worsening of NMO. NMO because of his immune pathological humoral [13] mechanisms is sensitive to corticosteroid and immunosuppressive drugs. Our patients had benefited from high doses of corticosteroid therapy with a recovery of motor functions.

\section{CONCLUSION}

NMO is an inflammatory and demyelinating pathology characterized by a higher frequency in young adults especially women. The importance of multicenter studies is crucial for mapping the disease in Africa. Determination of anti-NMO antibodies is interesting but limited in Africa access. The presence of clinical and para clinical signs especially MRI and neuro physiological Wingerchuk criteria could justify the establishment of an adequate therapy.

\section{REFERENCES}

[1] Lennon, VA., Wingerchuk, DM., Kryzer, TJ. et al. (2004). A serum autoantibody marker of neuromyelitis optica: distinction from multiple sclerosis. Lancet, 364, 2106-12.

[2] Lennon, VA., Kryzer, TJ., Pittock, SJ. et al.(2005). IgG marker of optic-spinal multiple sclerosis binds to the aquaporin-4 water channel. J Exp Med. 202, 473-7.

[3] Wingerchuk, DM., Lennon, VA., Lucchinetti, CF. et al. 2007). The spectrum of neuromyelitis optica. Lancet Neurol, 6, 805-15.

[4] Wingerchuck, DM., Hogancamp, WF., O'Brien, PC. et al. (1999). The clinical course of neuromyelitis optica (Devic's syndrome). Neurology, 53, 1107-14.

[5] Cabre, P., Gonzalez-Quevedo, A., Lannuzel, A. et al. 2009). Epidémiologie descriptive de la neuromyélite optique dans le bassin caral̂béen. Revue neurologique, 165, 676-83.

[6] Wingerchuk, DM., Lennon, VA., Pittock, SJ. et al. (2006). Revised diagnostic criteria for neuromyelitis optica. Neurology, 66, 1485-9. 
[7] Sellner, J., Hemmer, B., Mühlau, M. (2010) The clinical spectrum and immunobiology of parainfectious neuromyelitis optica (Devic) syndromes. Journal of Autoimmunity, 34, 3719.

[8] Papeix, C., Tourbah, A., Houeto, J-L. et al. (2005). Différencier la neuromyélite optique de Devic et la forme optico-spinal de SEP : valeur de l'IRM. Rev Neurol, 161 (1), 34-5.

[9] De Seze, J., Stojkovic, T., Ferriby, D. et al. (2002). Devic's neuromyelitis optica: clinical, laboratory, MRI and outcome profile. Journal of the Neurological Sciences, 197, 57-61.

[10] El Otmani, H., Rafai, MA., Moutaouakil, F. et al. (2005). La neuromyélite optique au Maroc: Étude de neuf cas. Rev Neurol, 161 (12), 11916.

[11] Djemal, M., Ben Salah, M., Ben Hlima, N. et al. (2007). Neuromyélite optique de Devic chez l'enfant : à propos de 1 cas, avec revue de la littérature. Archives de pédiatrie, 14, 1337-40.

[12] Déral-Stéphant, V., Roux-Lelièvre, C., Vignal, R. et al. (2008). Neuromyélite optique de Devic : discussion diagnostique après dix ans d'évolution d'une neuropathie optique bilatérale sévère. J Fr Ophtalmol, 31 (7), 705-9.
[13] Bonnan, M., Olindo, S., Signate, A. et al. (2006) La neuromyélite optique rémittente : données neuroradiologiques. Rev Neurol, 162 (5), 595-602.

[14] Gillain, N., Fumal, A., Minon, JM. (2006). Bandes oligoclonales et index IgG interprété selon Reiber dans les maladies inflammatoires du système nerveux central. Immunoanal Biol Spéc, 21, 348-56.

[15] Barateau, L., Papillon, G., Olivier, N. et al. (2012). Neuromyélite optique à $\mathrm{AC}$ AQP4/NMO-IGG négatif : à propos de 3 observations. Revue Neurologique, 168, 1-39.

[16] Papeix, C. (2006). Maladie de Devic. Presse Med, 35, 1703-6.

[17] De Sèze, J., Collongues, N., Blanc, F. et al. (2009). Intérêt de l'IRM non conventionnelle dans la neuromyélite optique de Devic. Revue neurologique, 165, 2-3.

[18] Garcia, T., Tourbah, A., Setrouk, E., Ducasse, A. et al. (2012). Tomographie par cohérence optique (OCT) en neuro-ophtalmologie. J Fr Ophtalmol, 35, 454-66.

[19] Bencherifa, F., Bourassi, A., Mellal, Z. et al. (2007). Neuromyélite optique de Devic survenue au cours d'une grossesse. J Fr Ophtalmol, 30 (7), 737-743.

Citation: Dadah Samy Moahmed Lemine, et al. Devic Disease in Senegal, a West African Country: about Five Cases. ARC Journal of Neuroscience.2017; 2(1):3-9. doi:dx.doi.org/10.20431/2456-057X.0201002.

Copyright: (c) 2017 Authors. This is an open-access article distributed under the terms of the Creative Commons Attribution License, which permits unrestricted use, distribution, and reproduction in any medium, provided the original author and source are credited. 